\title{
«Bien dire et bien aprandre», La volonté didactique dans la littérature médiévale (tome II)
}

\section{Martina Crosio}

\section{(2) OpenEdition}

1 Journals

\section{Édition électronique}

URL : http://journals.openedition.org/studifrancesi/1227

DOI : 10.4000/studifrancesi. 1227

ISSN : 2421-5856

Éditeur

Rosenberg \& Sellier

\section{Édition imprimée}

Date de publication : 1 décembre 2015

Pagination : 560-561

ISSN : 0039-2944

\section{Référence électronique}

Martina Crosio, « «Bien dire et bien aprandre», La volonté didactique dans la littérature médiévale (tome II) », Studi Francesi [En ligne], 177 (LIX | III) | 2015, mis en ligne le 01 décembre 2015, consulté le 07 janvier 2021. URL : http://journals.openedition.org/studifrancesi/1227 ; DOI : https://doi.org/10.4000/ studifrancesi. 1227

Ce document a été généré automatiquement le 7 janvier 2021.

\section{(c)}

Studi Francesi è distribuita con Licenza Creative Commons Attribuzione - Non commerciale - Non opere derivate 4.0 Internazionale. 


\title{
«Bien dire et bien aprandre», $L a$ volonté didactique dans la littérature médiévale (tome II)
}

\author{
Martina Crosio
}

\section{RÉFÉRENCE}

«Bien dire et bien aprandre», Revue de Médiévistique. La volonté didactique dans la littérature médiévale (tome II) 30, 2014.

1 Ce deuxième tome complète les Actes des journées d'étude lilloises présentés ci-dessus.

2 Alice LAMY consacre son article à la Cosmographia de Bernard Silvestre, œuvre totalisante qui réunit anciens et nouveaux savoirs, ainsi que des données scientifiques et des conceptions philosophiques parfois inconciliables, et qui aspire à maîtriser et à transmettre la totalité des connaissances. Le prosimètre, avec son style varié et son mélange de genres, se révèle la forme idéale pour essayer d'organiser cette matière indomptable. La volonté didactique et pédagogique de Bernard doit néanmoins se mesurer avec un savoir mystérieux et caché qui lui échappe sans cesse et que seul le langage imagé de la poésie peut dévoiler en partie (La volonté didactique de Bernard Silvestre dans la "Cosmographia", un idéal poétique vecteur de savoirs universels, pp. 7-24).

Chloé chalumeau s'interroge sur le rôle que l'insertion de l'île Tournoyante joue dans l'espace fictionnel de l'Estoire del Saint Graal. Cette œuvre, qui associe les savoirs incompatibles de la Bible et de la physique antique, parvient à combiner le propos édifiant de la Vulgate avec une explication scientifique du monde. En poussant plus loin l'interprétation de cet épisode, C.C. reconnaît dans l'île, qui subit l'attraction contradictoire du ciel et de la terre, l'image du roman qui oscille également entre la tentation didactique et le plaisir de la pure narration (L'île Tournoyante, lieu de la difficile coexistence des savoirs dans l'“"Estoire del Saint Graal", pp. 25-38). 
4 En étudiant les descriptions des mirabilia orientaux dans le Roman de Toute Chevalerie de Thomas de Kent, Huguette LEGROS analyse leurs formes, leurs fonctions et les rapports qu'elles entretiennent avec la fiction. Si le but premier de Thomas est de transmettre des connaissances pseudo-scientifiques à ses lecteurs, ces digressions se révèlent tout aussi nécessaires à la compréhension du sens ultime de l'itinéraire oriental d'Alexandre: un chemin de croissance personnelle et spirituelle à la découverte du divin (Insertions et significations des discours encyclopédiques dans le "Roman de Toute Chevalerie" de Thomas de Kent, pp. 39-54).

5 Le traitement des mirabilia dans une version tardive (fin $d_{u} \mathrm{xv}^{\mathrm{e}}$ siècle) du Devisement du Monde (1298) est au cœur de la contribution de Denis LORÉE. Dans les pages concernant la merveille persane du puits ardent, le remanieur détourne le sens initial du récit polien pour proposer une interprétation apologétique du phénomène. Il y a donc là glissement de l'écriture objective et du désir didactique du Vénitien vers une perspective réflexive et heuristique dans les interpolations tardives ('Rien de tout cela n'est vrai...' À propos de quelques interpolations tardives $d u$ "Devisement $d u$ Monde", pp. 55-70).

6 Giacomo GIACOMAzzI relève chez Thomas la volonté d'attribuer plusieurs niveaux de sens au célèbre épisode du philtre dans le Roman de Tristan. Analoguement aux théologiens du XII ${ }^{\mathrm{e}}$ siècle, qui étudient la nature en tant que integumentum d'une réalité différente, Thomas cache derrière le motif de la folie d'amour une profonde réflexion sur l'âme humaine (Pouvoir et signification du philtre dans le "Roman de Tristan" de Thomas d'Angleterre: «la rhétorique de la vérité», pp. 73-80).

7 Le but de l'étude de Marie-Geneviève GROSSEL est de relever la présence du propos didactique dans la lyrique des trouvères. Le registre sentencieux peut s'y exprimer à travers un simple proverbe, voire occuper plusieurs strophes du chant, qui se fait ainsi véritable chastoiement. Cette intention didactique paraît s'amplifier au cours du temps, ce qui peut s'expliquer par la tentative des poètes de faire revivre la doctrine, désormais vieillie, de la Fine Amour (De la sentence au 'chastoiement': la tentation didactique dans la chanson de trouvères, pp. 81-97).

Dans un article dense, Catherine GAULLIER-BOUGASSAS met en relief la valeur didactique du Roman du Châtelain de Coucy. En relatant la légende d'un trouvère historique, Jakemés exploite le lyrisme des poèmes enchâssés dans l'intrigue romanesque pour célébrer l'idéal de la fin'amor incarné par le couple protagoniste. Si les circonstances de la double mort des amants sacralisent et légitiment leur passion adultère en conciliant l'amour courtois avec la foi chrétienne, le discours autobiographique réaffirme lui aussi les ambitions didactiques de l'auteur ("Le Roman du Châtelain de Coucy et de la Dame de Fayel": un miroir de l'amour idéal?, pp. 99-113).

9 En proposant l'analyse de trois pièces tirées du répertoire des conduits-genre poétique latin mis en musique - Anne-Zoé RILLON-MARNE vise à montrer l'apport de la mélodie à la transmission du message didactique porté par le texte. L'entrelacs des mots et du chant permet d'atteindre les cœurs des fidèles et contribue à véhiculer d'une façon plus efficace l'enseignement moral offert par la poésie (La musique comme outil didactique dans la lyrique latine (XII ${ }^{e}$-XIII ${ }^{e}$ siècles), pp. 115-132).

Intégré sans fractures à la diégèse, le didactisme amoureux de Flamenca exploite une intertextualité savante, tout en faisant un usage modéré et ponctuel des figures allégoriques. Valérie FASSEUR souligne la confiance accordée par l'auteur à la supériorité 
de l'expérience individuelle au détriment de tout savoir livresque et de la généralisation des discours théoriques (Le didactisme amoureux de "Flamenca": entre mémoire savante et volonté d'expérience, pp. 133-147).

11 Commerçant et écrivain amateur, Philippe de Vigneulles est l'auteur au début du XVI siècle des Cent Nouvelles Nouvelles, œuvre qui s'inscrit dans la riche tradition des recueils de récits brefs. La visée didactique du prologue et les nombreux enseignements parsemés dans les nouvelles permettent à Alexandra VELISSARIOU de mettre en évidence l'habilité de Philippe à concilier la narration d'histoires amusantes avec sa volonté édifiante ("Des nouvelles bonnes à oyr»: la fonction didactique des "Cent Nouvelles Nouvelles" de Philippe de Vigneulles, pp. 149-164).

12 Consacrant son étude au Livre de Caradoc, Maria colombo timelli compare la mise en prose anonyme de 1530 avec la source en vers (Première Continuation de Perceval, version longue) antérieure de trois siècles. Les ajouts et les interventions du prosateur révèlent sa ferme intention pédagogique aussi bien que la nouvelle interprétation qu'il donne du récit: à l'histoire initiale d'un couple idéal il superpose sa volonté de proposer à ses lecteurs un modèle féminin à imiter (Le "Livre de Caradoc" dans la version en prose de 1530: une 'école des femmes'?, pp. 165-178). 